\title{
ANALISIS SELF EFFICACY PESERTA PELATIHAN PENANGANAN KEGAWATDARURATAN PADA KORBAN BALITA TENGGELAM
}

\section{ANALYZE THE SELF-EFFICACY OF TRAINING PARTICIPANTS IN EMERGENCY HANDLING OF TODDLERS DROWNING}

\author{
Christianto Nugroho $^{1 *}$, Suryono ${ }^{2}$ \\ ${ }^{12}$ STIKes Pamenang, \\ *christiantonug@gmail.com
}

\begin{abstract}
Abstrak
Tenggelam atau drowning didefinisikan sebagai kematian karena akfiksia akibat terendam pada cairan, terutama air. Permasalahan mitra yang dirumuskan yaitu rendahnya pengetahuan, keterampilan dan kepercayaan diri (Self Efficacy) dalam penanganan kegawatdaruratan tenggelam pada balita dan upaya antisipasi yang dapat dilakukan di rumah untuk mencegah resiko kecelakaan tenggelam pada balita.Tujuan penelitian ini adalah menganalisis Self Efficacy peserta pelatihan penanganan kegawatdaruratan pada korban balita tenggelam di Desa Darungan Kecamatan Pare Kabupaten Kediri.

Desain Penelitian ini menggunakan pendekatan One Group Pre Test-Post Test Design, pengumpulan data dilakukan dengan panduan kuesioner. Populasi penelitian adalah keseluruhan peserta pelatihan kegawatdaruratan pada korban balita tenggelam di desa Darungan yang berjumlah 15 orang, sampel menggunakan total sampel yaitu 15 responden. Variabel independent penelitian ini adalah pelatihan kegawatdaruratan korban balita tenggelam dan variabel dependent panelitian ini adalah Self Efficacy. Pengambilan data dilakukan dengan memberikan kuesioner yang mengukur tingkat self efficacy peserta sebelum dilakukan pelatihan dan setelah dilakukan dilakukan pelatihan. Kemudian data ditabulasi untuk melihat tingkat Self Efficacy dan dilakukan uji beda menggunakan uji Paired t-test.

Hasil yang didapatkan pada penelitian ini adalah Self Efficacy sebelum dilakukan pelatihan memiliki rata rata di skor 67 dalam kategori rata-rata rendah $(<69 \%)$ dan Self Efficacy setelah dilakukan pelatihan memiliki rata rata di skor 95,4 dalam kategori rata-rata sedang (69-99\%) serta analisis pre dan post pelatihan diketahui sig. ( 2 tailed) sebesar $0,000<0,05$, bahwa terdapat perbedaan yang nyata antara hasil Self Efficacy peserta pelatihan penanganan kegawatdaruratan pada korban balita tenggelam pada data pretest dan post test, artinya bahwa pelatihan penanganan kegawatdaruratan pada balita tenggelam memberikan pengaruh yang nyata terhadap perubahan Self Efficacy peserta pelatihan.

Dari penelitian ini di simpulkan pelatihan penanganan kegawatdaruratan pada korban balita tenggelam memberikan efek terhadap peningkatan Self Efficacy masyarakat darungan.
\end{abstract}

Kata kunci : Self Efficacy, Pelatihan, Masyarakat

\begin{abstract}
Drowning or drowning was defined as death due to akfiksia due submerged in fluids, especially water. The partner problems formulated are low knowledge, skills and self-confidence (Self Efficacy) in handling emergency drowning in toddlers and anticipatory efforts that can be done at home to prevent the risk of drowning accidents in toddlers. The purpose of this study was to analyze the self-efficacy of training participants in emergency handling of toddlers drowning in Darungan Village, Pare District, Kediri Regency.

The design of this study used the One Group Pre-Test-Post-Test Design approach, data collection was carried out with a questionnaire guide. The study population is the overall trainee emergency in toddler drowning victims in the village darungan which totaled 15 people, a sample using a total sample of 15 respondents. The independent variable of this research is Training in Emergency Handling Of Toddlers Drowning and the dependent variable of this research is Self Efficacy. Data
\end{abstract}


were collected by questionnaire that measures the level of self-efficacy of participants prior to the training and after the training is done. Then the data were tabulated to see the level of self efficay and different test performed using a Paired t-test.

The results obtained in this study are that self-efficacy before training has an average score of 67 in the low average category ( $<69 \%)$ and self-efficacy after training has an average score of 95.4 in the medium average category ( $69-99 \%)$ as well as the pre and post training analysis, it is known that sig. $(2$ tailed) of $0.000<0.05$, that there is a significant difference between the results of the self-efficacy of training participants in emergency handling of children under five drowning in the pretest and posttest data, meaning that Emergency handling training for drowning toddlers has a significant effect on changes in self-efficacy of training participants.

This research concluded emergency handling training in toddler drowning victims have an effect on self-efficacy enhancement darungan society.

\section{Keywords : Self-Efficacy, Training, Community}

\section{PENDAHULUAN}

Tenggelam atau drowning didefinisikan sebagai kematian karena akfiksia akibat terendam pada cairan, terutama air. Penumpukan medium cair mengakibatkan kerusakan tractus respiratorius primer (Suryono, 2020). Permasalahan mitra yang dirumuskan yaitu rendahnya pengetahuan, keterampilan dan kepercayaan diri dalam penanganan kegawatdaruratan tenggelam pada balita dan upaya antisipasi yang dapat dilakukan di rumah untuk mencegah resiko kecelakaan tenggelam pada balita (Suryono, 2020)

Seseorang yang hanya memiliki pengetahuan, sikap, dan ketrampilan tertentu tanpa adanya self efficacy yang tinggi, menunjukkan keyakinan bahwa dirinya mampu untuk melakukan sesuatu, maka kecil kemungkinan sesorang tersebut akan melakukan tindakan atau perilaku tersebut (Edberg, 2010) (Nugroho, 2015). Self efficacy mempengaruhi bagaimana seseorang berpikir, merasa, memotivasi diri sendiri, dan bertindak. Self efficacy sangat berpengaruh pada bagaimana seseorang membuat keputusan dan bertindak sesuai dengan yang diharapkan (Nugroho, 2015) (Atak, Gurkan and Kose, 2008).

Seseorang yang hanya memiliki pengetahuan, sikap, dan ketrampilan tertentu tanpa adanya self efficacy yang tinggi, menunjukkan keyakinan bahwa dirinya mampu untuk melakukan sesuatu, maka kecil kemungkinan sesorang tersebut akan melakukan tindakan atau perilaku tersebut (Edberg, 2010). Self efficacy mempengaruhi bagaimana seseorang berpikir, merasa, memotivasi diri sendiri, dan bertindak. Self efficacy sangat berpengaruh pada bagaimana seseorang membuat keputusan dan bertindak sesuai dengan yang diharapkan (Atak, Gurkan and Kose, 2008). Self efficacy merupakan indikator positif dari core self evaluation untuk melakukan evaluasi diri yang berguna untuk memahami diri. Self efficacy merupakan salah satu aspek pengetahuan tentang diri yang paling berpengaruh dalam kehidupan manusia seharihari karena ikut mempengaruhi individu dalam menentukan tindakan yang akan dilakukan untuk mencapai suatu tujuan, termasuk di dalamnya perkiraan terhadap tantangan yang akan dihadapi. Self efficacy adalah penilaian seseorang mengenai kemampuan dirinya untuk mengorganisasikan dan mengarahkan perilakunya dalam mencapai kinerja tertentu (Bandura, 2010). Menurut Robbins semakin tinggi self efficacy, maka semakin tinggi pula keyakinannya untuk sukses dalam bekerja. Oleh karena itu, ketika individu berada dalam situasi yang sulit dan mengancam, individu yang memiliki self efficacy rendah akan mengurangi usaha kerja atau memilih untuk menyerah. Sebaliknya, individu dengan self efficacy yang tinggi akan berusaha keras untuk menghadapi tantangan dalam pekerjaannya tersebut (Robbins, 2003).

Efikasi diri dikembangkan oleh empat sumber utama yang berpengaruh, antara lain : Performance Accomplishments (pengalaman penguasaan tindakan) yaitu mengelola tuntutan tugas dengan berhasil, vicarious experience (pengalaman permodelan) adalah dengan melihat orang - orang yang mirip dengan dirinya, Verbal persuasion (persuasi verbal) tentang kemampuan untuk berhasil dalam kegiatan tertentu, Somatic and emotional state (kondisi somatic dan emosional), menunjukkan kekuatan pribadi dan kerentanan (Bandura, 
1997). Dengan memberikan pelatihan penanganan kegawatdaruratan pada korban balita tenggelam diharapkan dapat meningkatkan self efficacy diri masyarakat di darungan untuk memberikan pertolongan pertama yang benar.

\section{METODE}

Desain Penelitian ini menggunakan pendekatan One Group Pre Test-Post Test Design, dilaksanakan di bulan Februari 2019 di kelompok Paguyuban Petani Lele "Mini Tani Lestari" Desa Darungan Kecamatan Pare Kabupaten Kediri. Pengumpulan data dilakukan dengan panduan kuesioner. Variabel independent penelitian ini adalah pelatihan kegawatdaruratan korban balita tenggelam dan variabel dependent panelitian ini adalah Self Efficacy. Populasi keseluruhan peserta pelatihan kegawatdaruratan pada korban balita tenggelam di Desa Darungan Kabupaten Kediri yang berjumlah 15 orang, sampel menggunakan total sampel yaitu 15 responden. Pengambilan data dilakukan dengan memberikan kuesioner yang mengukur tingkat Self Efficacy peserta sebelum dilakukan pelatihan dan setelah dilakukan dilakukan pelatihan dilakukan pengukuran ulang Self Efficacynya. Kriteria self efficacy menurut bandura dibagi menjadi 3 bagian yaitu Tinggi : >99\%, Sedang: 6999\%, Rendah: <69\% (Bandura, 1997). Perbedaan self efficacy peserta pelatihan sebelum dan setelah pelaksanaan pelatihan digunakan uji Paired t-test dengan menggunakan SPPS dengan tingkat kesalahan yang digunakan yaitu $5 \%$ atau 0,05 , artinya apabila $\mathrm{p}$ value $<0,05$ maka Ho ditolak, H1 diterima artinya bahwa pelatihan kegawatduratan pada korban balita tenggelam di desa darungan memberikan efek terhadap peningkatan self efficacy peserta.

\section{HASIL}

Dalam penelitian ini didapatkan jumlah responden 15 orang yang mengikuti program Pelatihan penanganan kegawatdaruratan pada korban balita tenggelam di desa Darungan di bulan Februari 2020.

1. Self Efficacy sebelum dilakukan Pelatihan Penanganan kegawatdaruratan pada korban balita tenggelam

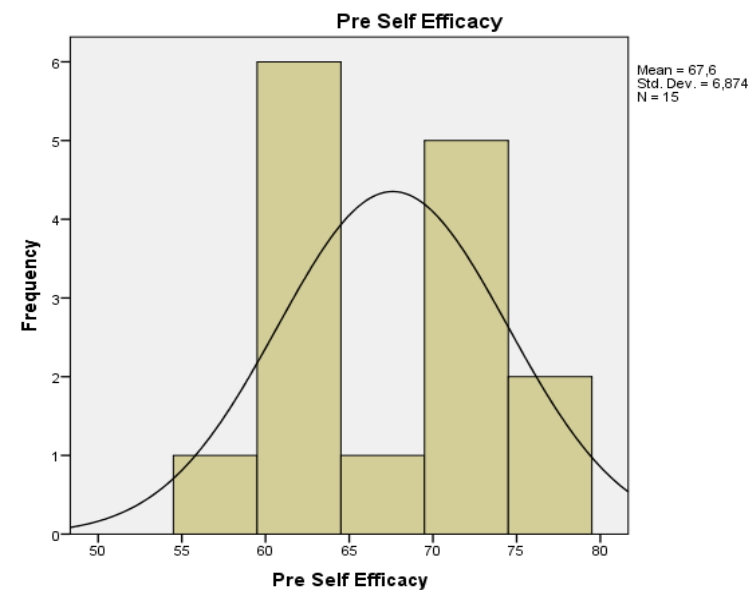

Gambar 1. Distribusi self efficacy sebelum dilakukan pelatihan

Self Efficacy sebelum dilakukan pelatihan memiliki rata rata di skor 67 dalam kategori rata-rata rendah $(<69 \%)$.

2. Self Efficacy setelah dilakukan Pelatihan Penanganan kegawatdaruratan pada korban balita tenggelam

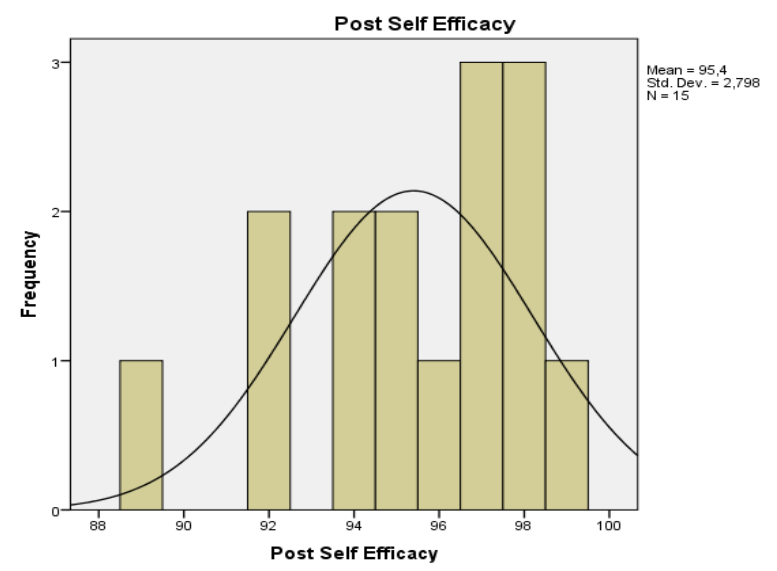

Gambar 2 Distribusi Self Efficacy sesudah dilakukan pelatihan

Self Efficacy setelah dilakukan pelatihan memiliki rata rata di skor 95,4 dalam kategori rata-rata sedang $(69-99 \%)$.

3. Analisis Self Efficacy Peserta Pelatihan Penanganan kegawatdaruratan pada korban balita tenggelam

Tabel 1. Hasil uji Paired t-test pre dan post Self Efficacy peserta Pelatihan penanganan 
kegawatdaruratan pada korban balita tenggelam di desa darungan

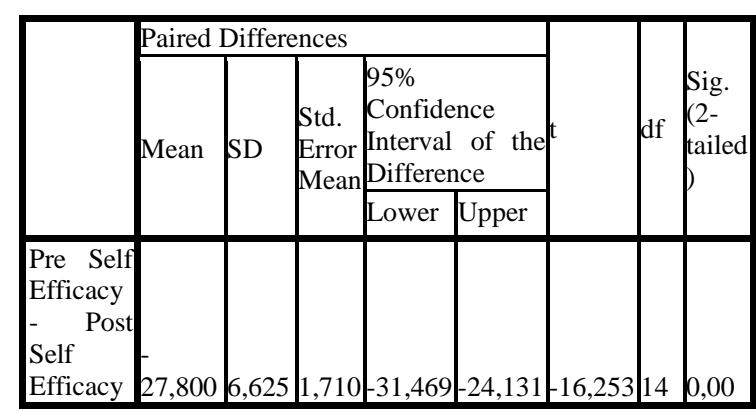

Hasil yang didapatkan pada penelitian ini adalah bahwa diketahui nilai sig.(2 tailed) sebesar $0,000<0,05$, bahwa terdapat perbedaan yang nyata antara hasil Self Efficacy peserta pelatihan penanganan kegawatdaruratan pada korban balita tenggelam pada data pretest dan posttest, artinya bahwa pelatihan penanganan kegawatdaruratan pada balita tenggelam memberikan pengaruh yang nyata terhadap perubahan Self Efficacy peserta pelatihan.

\section{PEMBAHASAN}

1. Self Efficacy sebelum dilakukan Pelatihan Penanganan kegawatdaruratan pada korban balita tenggelam Self efficacy sebelum dilakukan pelatihan memiliki rata rata di skor 67 dalam kategori rata-rata rendah ( < 69\%). Menurut Bandura Self efficacy dapat ditumbuhkan dan dipelajari melalui mastery experience (pengalaman keberhasilan). Sumber berpengaruh bagi self efficacy adalah pengalaman-pengalaman tentang penguasaan (mastery experience), yaitu performaperforma yang sudah dilakukan di masa lalu (Bandura, 2010). Hal ini sesuai dengan pernyataan dari salah satu peserta sebelum mengikuti pelatihan kegawatdaruratan korban tenggelam yang menyatakan bahwa selama ini belum pernah mendapatkan materi tentang cara menolong korban tenggelam, sehingga belum mengetahui bagaimana cara menolong korban tenggelam yang benar, hal ini memberikan gambaran juga bahwa peserta pelatihan memiliki self efficacy yang masih rendah.

2. Self Efficacy setelah dilakukan Pelatihan Penanganan kegawatdaruratan pada korban balita tenggelam Self efficacy setelah dilakukan pelatihan memiliki rata rata di skor 95,4 dalam kategori rata-rata sedang $(69-99 \%)$.

Penelitian sebelumnya telah menunjukkan (Davazdahemami, Behrooz; Luse, Andy; Scheibe, Kevin P.; and Townsend, 2018) bahwa dampak pelatihan secara positif mempengaruhi efikasi diri internet peserta pelatihan selama kursus berlangsung.

Melihat hasil dan teori serta penelitian sebelumnya self efficacy peserta pelatihan kegawatdaruratan korban tenggelam meningkat setelah dilakukan pelatihan, hal ini menunjukkan bahwa tehnik pelatihan bisa memberikan efek terhadap peningkatan self efficacy peserta pelatihan. Semakin tinggi self efficacy peserta harapannya semakin besar pula kepercayaan peserta untuk melakukan pertolongan secara mandiri apabia terjadi kegawatdaruratan korban tenggelam.

3. Analisis Self Efficacy Peserta Pelatihan Penanganan Kegawatdaruratan pada korban balita tenggelam

Hasil yang didapatkan pada penelitian ini adalah bahwa diketahui nilai sig.(2 tailed) sebesar $0,000<0,05$, bahwa terdapat perbedaan yang nyata antara hasil self efficacy peserta pelatihan penanganan kegawatdaruratan pada korban balita tenggelam pada data pretest dan posttest, artinya bahwa pelatihan penanganan kegawatdaruratan pada balita tenggelam memberikan pengaruh yang nyata terhadap perubahan self efficacy peserta pelatihan.

Berdasarkan penelitian penelitian yang terdahulu bahwa memang self efficacy dipenaruhi oleh beberapa faktor. Pengetahuan yang meningkat dari hasil penyuluhan juga bisa meningkatkan self efficacy peserta penyuluhan, seperti halnya metode intervensi enhancement bisa meningkatan self efficacy pada pasien diabetes melitus (Nugroho, 2015), Prediktor self efficacy salah satunya disebabkan karena adanya peningkatan pengetahuan dari peserta pelatihan (Wei et al., 2013), hal ini juga ditunjang oleh penelitian Zahra bahwa faktor self efficacy meningkat disebabkan oleh metode pemberian pelatihan meliputi mendongeng atau ceramah (Vahdaninya et al., 2015).

Efikasi diri dikembangkan oleh empat sumber utama yang berpengaruh, antara lain : Performance Accomplishments (pengalaman penguasaan tindakan) yaitu mengelola tuntutan tugas dengan berhasil, vicarious experience 
(pengalaman permodelan) adalah dengan melihat orang - orang yang mirip dengan dirinya, Verbal persuasion (persuasi verbal) tentang kemampuan untuk berhasil dalam kegiatan tertentu, Somatic and emotional state (kondisi somatic dan emosional), menunjukkan kekuatan pribadi dan kerentanan (Bandura, 1997). Efikasi diri merupakan keyakinan dalam kemampuan seseorang untuk mengatur dan melaksanakan program tindakan yang diperlukan untuk mengelola situasi yang akan terjadi (Bandura, 1997). Hal ini menunjukkan bahwa ada faktor lain selain empat elemen self efficacy yang mempengaruhi self efficacy pada individu, walaupun factor tersebut tidak berdiri sendiri tetapi mempengaruhi secara bersama-sama, ini sesuai dengan teori Bandura yang menyatakan selain keempat sumber efficacy dan proses informasi dapat juga dipengaruhi dari karakteristik individu dan lingkungan. Secara ideal, self efficacy diperkuat melalui berbagai pengalaman yang berhubungan dan akan mempengaruhi perilaku selanjutnya. Seseorang akan memutuskan untuk berperilaku berdasarkan pada pemikiran reflektif, penggunaan pengetahuan secara umum, dan kemampuan untuk melakukan suatu tindakan.

Melihat hal tersebut diatas dapat disimpulkan bahwa pelatihan kegawatdaruratan korban tenggelam memberikan efek terhadap meningkatnya self efficacy.

\section{KESIMPULAN}

Pemberian Pelatihan penanganan kegawatdaruratan pada korban balita tenggelam memberikan efek terhadap peningkatan self efficacy masyarakat darungan untuk melakukan pertolongan pertama dengan baik dan benar.

\section{SARAN}

Berdasarkan penelitian ini perlu disarankan untuk semakin luas dilakukan peningkatan self efficacy denga membangun pengetahuan masyarakat terkait pertolongan pertama kegawat daruratan di desa.

\section{UCAPAN TERIMA KASIH}

Terima kasih kami ucapkan atas peran serta Stikes Pamenang dan LPPM Stikes Pamenang yang telah memberikan dukungan sehingga dapat berjalan kegiatan ini dan kepada Kepala desa serta kelompok Mina di
Desa Darungan yang telah memberikan kesempatan untuk melakukan penelitian dan pelatihan kegawatdaruratan

\section{DAFTAR PUSTAKA}

Atak, N., Gurkan, T. and Kose, K. (2008) '262_Atak', Australian Journal of Advanced Nursing, The, 26(2), p. 66. Available at: http://search.informit.com.au/documentSu mmary;dn=198857737071665;res=IELAP A.

Bandura, A. (1997) Self-Efficacy: The Exercise of Control. Worth Publishers. Available at: https://books.google.co.id/books?id=eJPN9g_o-EC.

Bandura, A. (2010) 'Self-Efficacy', The Corsini Encyclopedia of Psychology. (Major Reference Works), pp. 1-3. doi: https://doi.org/10.1002/9780470479216.co rpsy0836.

Davazdahemami, Behrooz; Luse, Andy; Scheibe, Kevin P.; and Townsend, A. M. (2018) 'Training, Self-Efficacy, and Performance; a Replication Study', AIS Transactions on Replication Research, 4(March), pp. 1-18. doi: 10.17705/1atrr.00023.

Edberg, M. (2010) Kesehatan Masyarakat, Teori Sosial dan Perilaku. Jakarta: EGC.

Nugroho, C. (2015) Improving Self-Efficacy Using Caring-Based Self-Efficacy Enhancement Intervention Program In Patients With Type 2 Diabetes Mellitus. Universitas Airlangga.

doi: 10.13140/RG.2.2.36810.18883.

Robbins, S. P. (2003) No Title. Jakarta: Gramedia. Available at: http://lib.ui.ac.id/detail.jsp?id=20100124.

Suryono, C. N. (2020) 'Pelatihan Penanganan Kegawatdaruratan Pada Korban Balita Tenggelam di Desa Darungan', Journal of Community Engagement in Health, 3(2), pp. 320-324. Available at: file://C:/Users/Chris/Downloads/89Article Text-334-1-10-20200921.pdf.

Vahdaninya, Z. et al. (2015) 'Training Based On Orem's Model On Knowledge, Attitude And Self-Efficacy Of Mothers In Preventing Domestic Accidents', Modern Care Journal, 12(3), pp. 119-124. Available at:https://www.sid.ir/en/Journal/ViewPape r.aspx?ID=515713.

Wei, Y.-L. et al. (2013) 'Self-efficacy of first aid for home accidents among parents with 0 to 4-year-old children at a metropolitan community health center in Taiwan', Accident Analysis \& Prevention, 52, pp. 182-187. doi: https://doi.org/10.1016/j.aap.2012.12.002. 